\title{
EPR and NMR Studies of Amorphous Aluminium Borates ${ }^{\dagger}$
}

\author{
Simion Simon, Andre van der Pol, Edward J. Reijerse, Arno P. M. Kentgens, Geert J. van Moorsel \\ and Engbert de Boer \\ Department of Molecular Spectroscopy, Faculty of Science, University of Nijmegen, Toernooiveld \\ 6525 ED Nijmegen, The Netherlands
}

\begin{abstract}
Amorphous aluminium borates, $\mathrm{Al}_{2(1-x)} \mathrm{B}_{2 x} \mathrm{O}_{3}$ with $0 \leqslant x \leqslant 0.5$, prepared from mixtures of aluminium nitrate, boric acid and glycerol, have been studied by EPR and ${ }^{27} \mathrm{Al}$ MASNMR as a function of composition and heattreatment temperature $\left(T_{\mathrm{t}} \leqslant 860^{\circ} \mathrm{C}\right)$. EPR studies showed the presence of physisorbed $\mathrm{NO}_{2}, \mathrm{NO}$ and $\mathrm{O}_{2}$ molecules, produced by decomposition reactions during the thermal treatment. The $\mathrm{O}_{2}$ molecules in the gaseous state were observed in a narrow temperature interval around $60 \mathrm{~K}$ and in the condensed phase at low temperature $(<20 \mathrm{~K})$. The $D$ value for condensed $\mathrm{O}_{2}$ amounts to $109 \mathrm{GHz}$, significantly lower than the value for 'free' $\mathrm{O}_{2}$, which is $119 \mathrm{GHz}$. Above $20 \mathrm{~K}$ the $\mathrm{NO}_{2}$ molecules in all samples rotate rapidly $\left(\geqslant 10^{7} \mathrm{~Hz}\right)$ about an axis parallel to the interatomic oxygen-oxygen direction; this mobility decreases with increasing heat-treatment temperature. Some EPR lines were tentatively ascribed to pairs or clusters of the abovementioned paramagnetic molecules.

${ }^{27} \mathrm{Al}$ MASNMR studies showed the presence of six-, five- and four-coordinate $\mathrm{Al}$ atoms, their relative concentrations being strongly dependent on the thermal history and composition of the samples. The fractions of tetraand penta-coordinated $\mathrm{Al}$ atoms were maximum at heat-treatment temperatures between 300 and $600^{\circ} \mathrm{C}$ and decreased considerably after the samples were exposed to air. Therefore the low coordinated $\mathrm{Al}$ atoms are predominantly located at the surface.
\end{abstract}

The decreased mobility of $\mathrm{NO}_{2}$ molecules, at high treatment temperatures, indicates that $\mathrm{NO}_{2}$ interacts strongly with the pore surface when it contains a large fraction of four-and five-coordinate $\mathrm{Al}$ ions.

Aluminas are extensively used as the supporting material in catalytic reactions. They are acid-base catalysts with a high surface area. ${ }^{1}$ Successful efforts have been made to prepare amorphous aluminas that exhibit a zeolite-type porosity. The pore configuration and dimensions depend on composition, preparation method and heat treatment. ${ }^{2,3}$

The addition of typical glass-forming components such as $\mathrm{SiO}_{2}, \mathrm{P}_{2} \mathrm{O}_{5}$ and $\mathrm{B}_{2} \mathrm{O}_{3}$, increases the stability of aluminas and leads also to new properties. ${ }^{4-8}$ The incorporation of transition-metal ions or rare-earth metal elements gives these materials interesting optical, magnetic and catalytic properties. $^{9-12}$ Amorphous aluminium borates with high surface areas can be prepared by a sol-gel method from solutions of aluminium salts and boric acid using ammonium hydroxide or methanol as precipitant. Recently a new method has been developed which also results in an amorphous material having a high surface area. This method involves the lowtemperature thermal decomposition of aluminium nitrate and boric acid sustained by the simultaneous oxidation of a suitable organic agent. Materials prepared this way were studied by thermal analysis methods, X-ray diffraction and FTIR spectroscopy. ${ }^{7,8}$ In this paper we report EPR and NMR studies of aluminium borates prepared according to this method. EPR studies of aluminium borates revealed the presence of physisorbed $\mathrm{NO}_{2}, \mathrm{NO}$ and $\mathrm{O}_{2}$ molecules which are produced by decomposition reactions during the thermal treatment. The mobility of the $\mathrm{NO}_{2}$ molecules, as reflected in the EPR spectra, was strongly dependent on the measurement temperature, the heat-treatment temperature and the sample composition. At low temperatures, EPR spectra of gaseous $\mathrm{O}_{2}$ as well as for $\mathrm{O}_{2}$ in the condensed phase were observed.

${ }^{27} \mathrm{Al}$ MASNMR studies revealed three signals at 6,30 and $60 \mathrm{ppm}$, corresponding to six-, five- and four-coordinate $\mathrm{Al}$, respectively. Their relative intensities were strongly dependent on the composition and the thermal history of the samples. The structural information obtained from ${ }^{27} \mathrm{Al}$

† This paper was presented at the 27th International ESR Conference at the University of Wales, Cardiff, 21st-25th March, 1994.
MASNMR is used to explain the different strength of the interactions between the identified paramagnetic gaseous species and the active sites of the pore surfaces, developed during the thermal treatment.

\section{Experimental}

Aluminium borate samples were prepared with composition $\mathrm{Al}_{2(1-x)} \mathrm{B}_{2 x} \mathrm{O}_{3}$ with $x=0,0.1,0.2,0.3,0.4$ and 0.5 . To a stoichiometric mixture of $\mathrm{Al}\left(\mathrm{NO}_{3}\right)_{3} \cdot 9 \mathrm{H}_{2} \mathrm{O}$ and $\mathrm{H}_{3} \mathrm{BO}_{3}$, glycerol was added as an organic reducing agent $(10 \mathrm{wt} . \%$ in all samples) and a small amount of distilled water. After the components had dissolved a single liquid phase was formed at room temperature. The clear solutions were heated to $95^{\circ} \mathrm{C}$ and after $c a .2 \mathrm{~h}$ spongy, bulky solid samples were obtained. At the end of the heating procedure decomposition reactions took place as apparent from emission of gaseous products. The conversion that takes place during the synthesis can be summarized as follows:

$$
\begin{aligned}
& 2\left[\mathrm{Al}\left(\mathrm{NO}_{3}\right)_{3} \cdot 9 \mathrm{H}_{2} \mathrm{O}\right] \rightarrow \mathrm{Al}_{2} \mathrm{O}_{3}+6 \mathrm{NO}_{2}+\frac{3}{2} \mathrm{O}_{2}+18 \mathrm{H}_{2} \mathrm{O} \\
& 6 \mathrm{NO}_{2} \rightleftarrows 6 \mathrm{NO}+3 \mathrm{O}_{2} \\
& 2 \mathrm{H}_{3} \mathrm{BO}_{3} \rightarrow \mathrm{B}_{2} \mathrm{O}_{3}+3 \mathrm{H}_{2} \mathrm{O} \\
& \text { glycerol oxidation }
\end{aligned}
$$

EPR and NMR measurements were carried out on samples treated for $30 \mathrm{~min}$ at various temperatures (see Fig. 1). For this procedure the solid material was crushed and placed in a cylindrical furnace for heating in the open air. Immediately after they had been heated the samples were sealed in quartz tubes for EPR measurements or placed in air-tight glass bottles for NMR measurements. Just before the beginning of the NMR measurements the samples were rapidly transferred to the spinners in order to keep hydration effects to a minimum.

The solid samples were white for $100 \leqslant T_{t} /{ }^{\circ} \mathrm{C}<150$, yellow-green for $150 \leqslant T /{ }^{\circ} \mathrm{C}<200$, yellow-brown for $200 \leqslant$ $T_{t} /{ }^{\circ} \mathrm{C}<300$, and white for $T_{t}>300^{\circ} \mathrm{C}$. The samples are denoted $\mathrm{AB}_{x}-T_{y}$, where $x$ refers to the boron content and $y$ to the treatment temperature $\left(y=T_{t} / 100\right)$. 


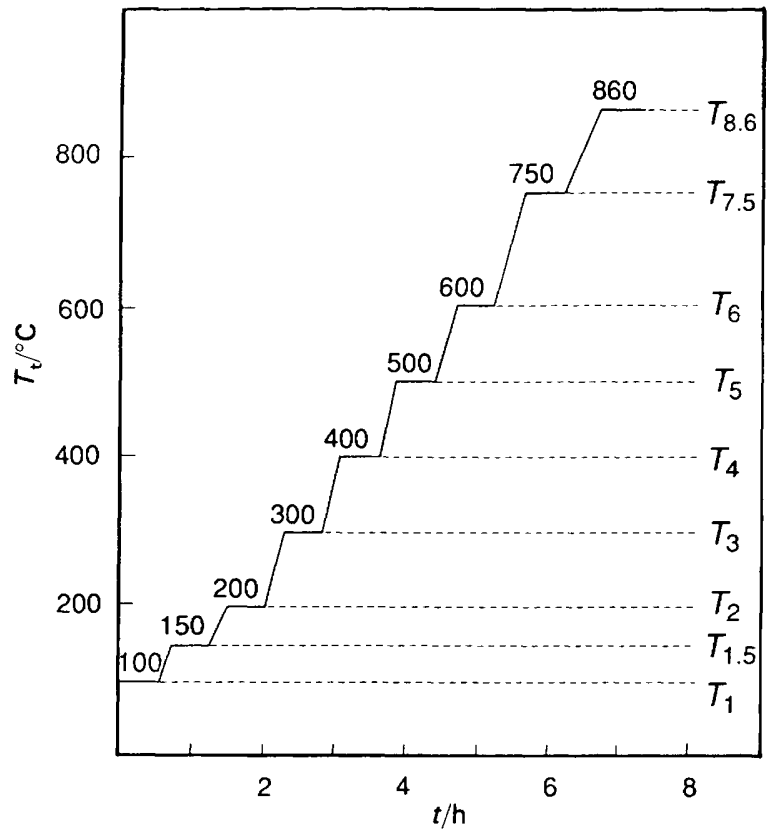

Fig. 1 Heat treatment diagram. The heating temperatures are denoted $T_{y}$, where $y=T_{v} / 100$.

EPR spectra were recorded on powdered samples on a Bruker ESP-380 X-band spectrometer at 5.8-300 K and at a static field between 0.05 and $13 \mathrm{kG}$. The average microwave frequency of the experiments was $9.3 \mathrm{GHz}$.

MASNMR measurements were carried out at room temperature on a Bruker AM-500 spectrometer equipped with a solid-state accessory, using a home-built probe head equipped with a Jakobsen $5 \mathrm{~mm}$ MAS assembly. Usually $1 \mu \mathrm{s}$ pulse excitations were applied and spinning speeds up to $14 \mathrm{kHz}$ were employed. Speetra are referenced with respect to an external $\mathrm{Al}\left(\mathrm{NO}_{3}\right)_{3}$ solution $\left[\mathrm{Al}\left(\mathrm{H}_{2} \mathrm{O}\right)_{6}{ }^{3+}\right]$.

\section{Results}

\section{EPR on Aluminium Borates}

EPR spectra representative for various stages of the synthesis process are shown in Fig. 2-7. All samples exhibited a relatively small EPR line at $c a .1550 \mathrm{G}$ with $g=4.23$ originating from $\mathrm{Fe}^{3+}$ impurities present in $\mathrm{Al}\left(\mathrm{NO}_{3}\right)_{3}$. This signal can be used as an internal standard for estimating the relative intensities of the other EPR signals.

$\mathrm{NO}_{2}$

A characteristic feature present in the EPR spectra of all samples is a number of lines in the $g \approx 2.0$ region extending over $c a .150 \mathrm{G}$. The highest intensity and best resolution was attained at low measurement temperatures. Fig. 3 and 4 illustrate the EPR spectrum of this signal as a function of temperature on a more expanded scale. For samples with $y<1.5$ the lines became practically undetectable at measurement $T_{\mathrm{m}}>150 \mathrm{~K}$ (Fig. 3), but for samples with $y \geqslant 3$ they were clearly observed even at room temperature (Fig. 4). These spectra can be ascribed to $\mathrm{NO}_{2}$ and are well described in the literature. ${ }^{13-19}$ In Fig. 3 the nitrogen hyperfine EPR lines are labelled with $x, y$ or $z$, where $y$ runs parallel to the interatomic oxygen-oxygen direction. The spectra show a clear temperature dependence. At low temperatures a powder-like spectrum is observed. Going to higher temperatures the $x$ and $z$ components merge, while the $y$ components keep their positions. From this behaviour it can be concluded that the $\mathrm{NO}_{2}$ molecules above $20 \mathrm{~K}$ rotate rapidly around an axis

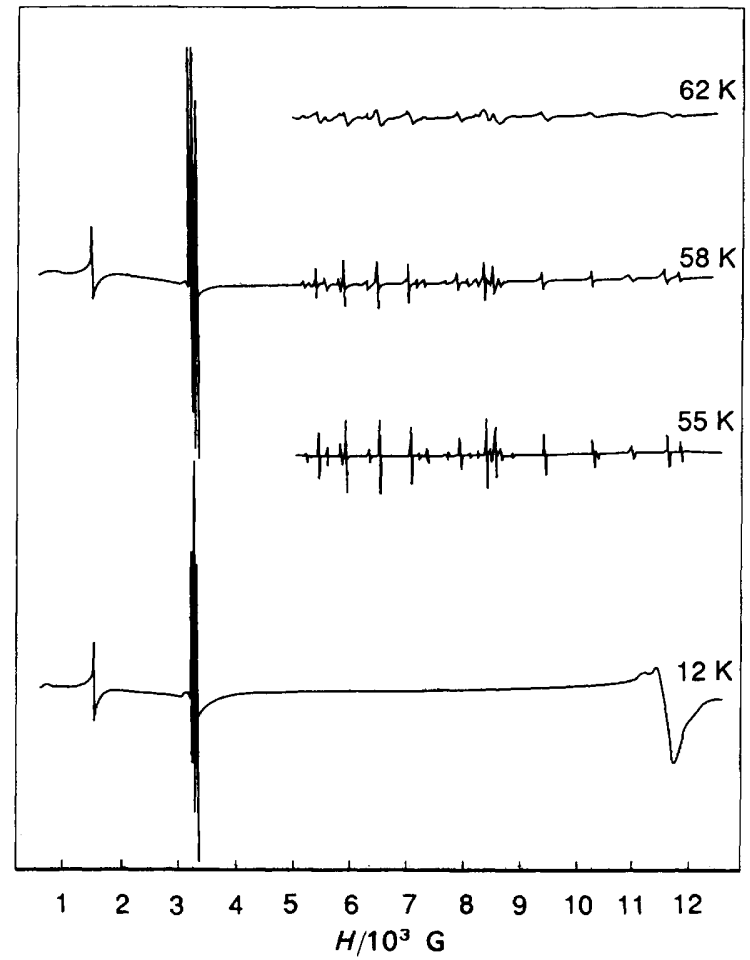

Fig. 2 EPR spectra of $\mathrm{AB}_{0.2}-T_{5}$ at: $12 \mathrm{~K}, 55 \mathrm{~K}, 58 \mathrm{~K}, 62 \mathrm{~K}$

parallel to the $y$ axis $\left(\geqslant 10^{7} \mathrm{~Hz}\right)$, as has been observed previously. ${ }^{15,18,19}$ For the sample $\mathrm{AB}_{0.2}-T_{1}$ this leads eventually to an isotropic spectrum $(T \geqslant 125 \mathrm{~K})$, whereas for the sample $\mathrm{AB}_{0.2}-T_{4}$ even at $300 \mathrm{~K}$ the rotation is still anisotropic. Thus the mobility of $\mathrm{NO}_{2}$ molecules depends on the thermal history of the samples. In the Discussion we will further elaborate on this. In Table 1 the magnetic parameters are listed together with those obtained for $\mathrm{NO}_{2}$ adsorbed on similar systems and for $\mathrm{NO}_{2}$ in the gas phase. From the similarity of the values in Table 1 it can be concluded that the adsorbed $\mathrm{NO}_{2}$ is not greatly distorted by the aluminium borate matrix.

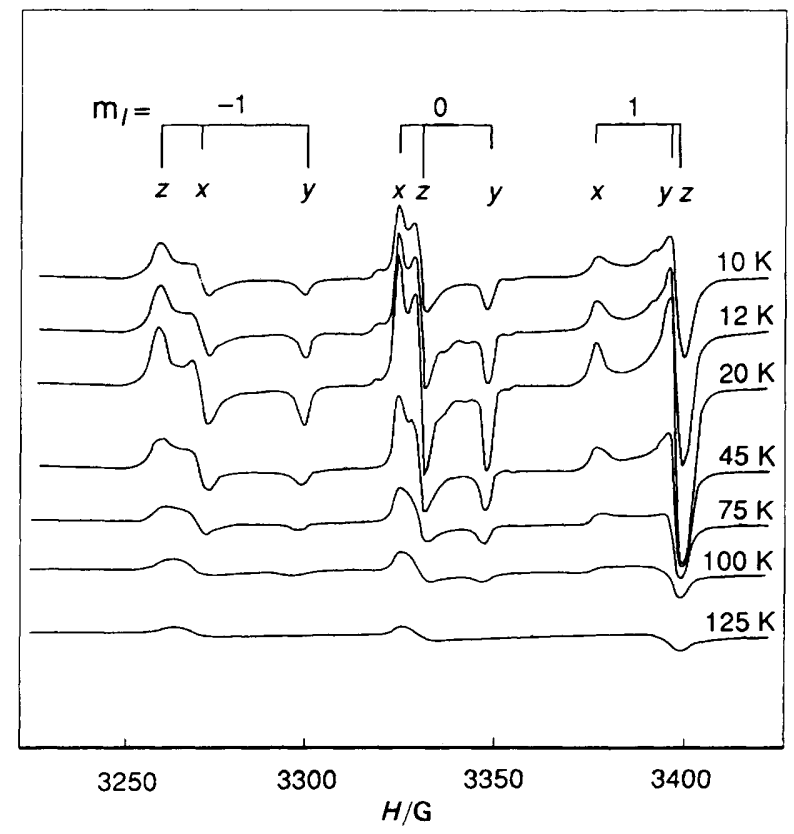

Fig. 3 Temperature dependence of the $\mathrm{NO}_{2}$ EPR spectrum of $\mathrm{AB}_{0.2}-T_{1}$. The assignment of hyperfine lines is shown. 


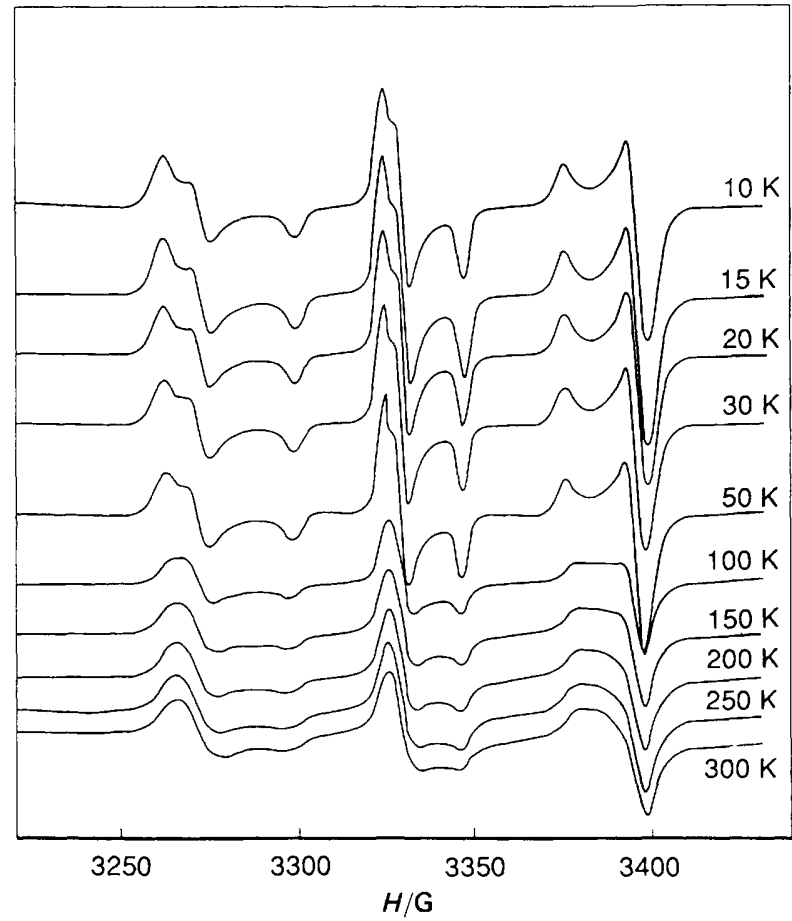

Fig. 4 Temperature dependence of the $\mathrm{NO}_{2}$ EPR spectrum of $\mathrm{AB}_{0.2}-T_{4}$

$\mathrm{O}_{2}$

In a relatively small temperature interval $(50-65 \mathrm{~K})$ a beautiful multiline spectrum was observed between 5 and $12.5 \mathrm{kG}$ (Fig. 2 and 7). Comparing this multiline signal with that observed for $\mathrm{O}_{2}$ in the gaseous state ${ }^{20,21}$ it can be inferred that this signal originates from $\mathrm{O}_{2}$ molecules in gaseous form probably present inside the pores of the sample. Above $c a$. $65 \mathrm{~K}$ this spectrum broadens beyond detection (see Fig. 2). At low temperatures it disappears and is replaced by a new strong signal at ca. $11.7 \mathrm{kG}$ (Fig. 2 and 7). Apparently decreasing the temperature causes the $\mathrm{O}_{2}$ molecules to condense on the surfaces of the pores and then gives rise to the well known signal at $c a .11 .7 \mathrm{kG}^{22-25}$ characteristic of $\mathrm{O}_{2}$ in the condensed phase. That the signal is due to $\mathrm{O}_{2}$ molecules produced by the decomposition reactions (1) and (2) is proven by the experiment illustrated in Fig. 5. In Fig. 5(a) the EPR spectrum is shown for the as-prepared sample $A B_{0.1^{-}}$ $T_{1.5}$. A very strong signal is observed at $11.7 \mathrm{kG}$. The quartz tube was then opened and connected to a vacuum system. After evacuation of the sample at room temperature the sample tube was sealed and subsequently the EPR spectrum was measured. A dramatic decrease of the signal intensity at $11.7 \mathrm{kG}$ was observed [see Fig. 5(b)]. A further short heat

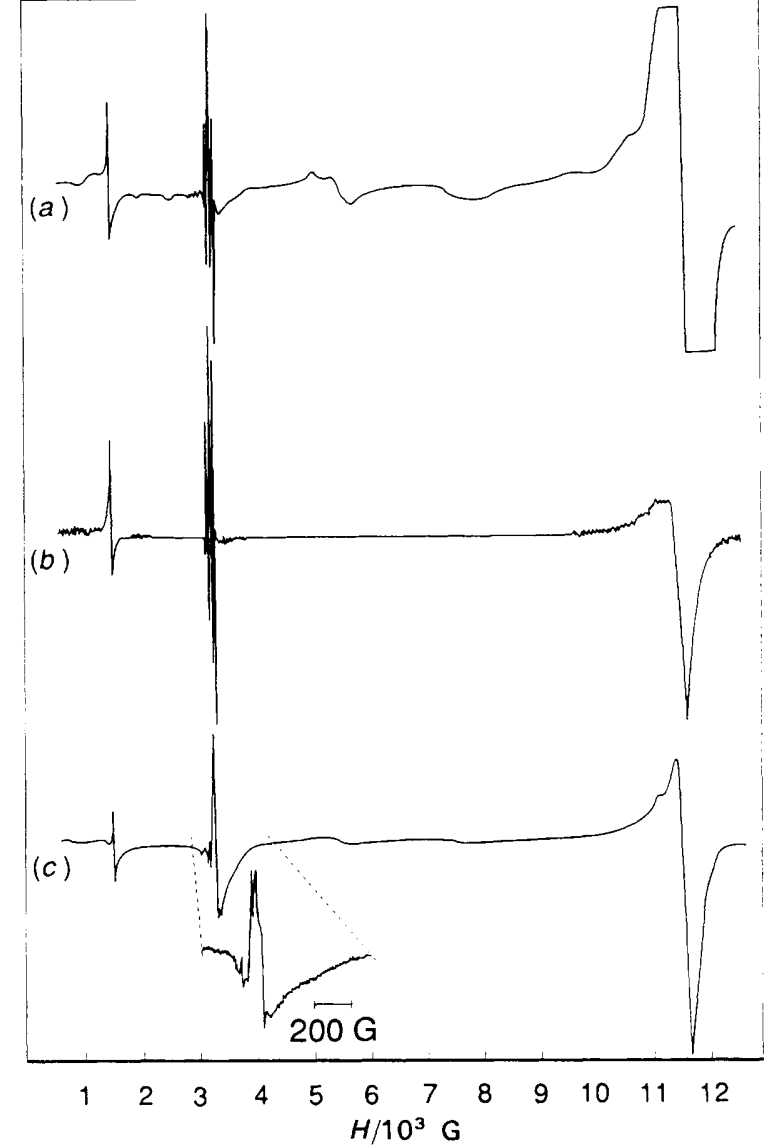

Fig. 5 EPR spectra of $\mathrm{AB}_{0.1}-T_{1.5}$ at $14 \mathrm{~K}:$ (a) before evacuation, (b) after evacuation at room temperature and $(c)$ after a new short ( $<1 \mathrm{~min}$ ) heat treatment at $150^{\circ} \mathrm{C}$

treatment of the sample in the closed tube $(<1 \mathrm{~min})$ at the same temperature $\left(150^{\circ} \mathrm{C}\right)$ resulted in an enhanced signal [Fig. 5(c)]. This enhancement must be due to $\mathrm{O}_{2}$ molecules produced by the decomposition reactions that occur during the short heat treatment.

The EPR spectrum of condensed triplet $\mathrm{O}_{2}$ has been analysed by using the following spin Hamiltonian

$$
H_{s}=D\left[S_{z}^{2}-\frac{1}{3} S(S+1)\right]+E\left(S_{x}^{2}-S_{y}^{2}\right)+\beta B_{0} \cdot g \cdot S
$$

and with the aid of the EPR simulation program MAGRES. ${ }^{28}$ An excellent fit was obtained using the following set of parameters: $g_{x}=g_{y}=2.02, \quad g_{z}=0.673$, $D=109.3 \mathrm{GHz}, E=0.075 \mathrm{GHz}$, Lorentzian linewidth $=200$ G. The dotted line in Fig. 7 shows the simulation. In passing we note that a perfect fit for the signal at $11.7 \mathrm{kG}$ could be obtained only by taking a non-zero asymmetry parameter $E$

Table 1 EPR parameters of $\mathrm{NO}_{2}$ molecules adsorbed on surface of various oxide matrices

\begin{tabular}{|c|c|c|c|c|c|c|c|c|c|}
\hline oxide matrix & $g_{x}$ & $g_{y}^{x}$ & $g_{z}$ & $g_{\text {iso }}$ & $\begin{array}{l}A_{x} / \\
\mathbf{M H z}\end{array}$ & $\begin{array}{l}A_{y}^{x} / \\
\mathrm{MHz}\end{array}$ & $\begin{array}{l}A_{z} / \\
\mathrm{MHz}\end{array}$ & $\begin{array}{l}A_{\text {iso }} \\
\mathrm{MHz}\end{array}$ & ref. \\
\hline $\mathrm{MgO}(93 \mathrm{~K})$ & 2.005 & 1.9915 & 2.002 & 1.9995 & 148 & 137 & 189 & 158 & 16 \\
\hline $\mathrm{ZnO}(77 \mathrm{~K})$ & 2.007 & 1.994 & 2.003 & 2.001 & 146.1 & 132 & 181.1 & 153.1 & 19 \\
\hline silica gel $(77 \mathrm{~K})$ & 2.004 & 1.9907 & 2.004 & 1.9996 & 165.7 & 137 & 165.7 & 156.1 & 18 \\
\hline Vycor $(4.8 \mathrm{~K})$ & 2.005 & 1.9913 & 2.0017 & 1.9994 & 140.3 & 128.2 & 183.5 & 150.7 & 19 \\
\hline zeolites $(77 \mathrm{~K})$ & 2.0043 & 1.9922 & 2.0017 & 1.9993 & 143.3 & 137.2 & 189.1 & 156.5 & 17 \\
\hline $\begin{array}{l}\text { aluminium borates } \\
\qquad(20 \mathrm{~K})\end{array}$ & 2.0015 & 1.9985 & 2.009 & 2.0066 & 144.5 & 133.0 & 185 & 154.1 & $-^{a}$ \\
\hline $\mathrm{NO}_{2}$ (gas) $(293 \mathrm{~K})$ & 2.0062 & 1.9910 & 2.0019 & 1.9997 & 128.0 & 126.0 & 184.9 & 146.5 & 13 \\
\hline
\end{tabular}

$x=y$ is the axis parallel with the interatomic oxygen-oxygen direction. ${ }^{a}$ Present work. 


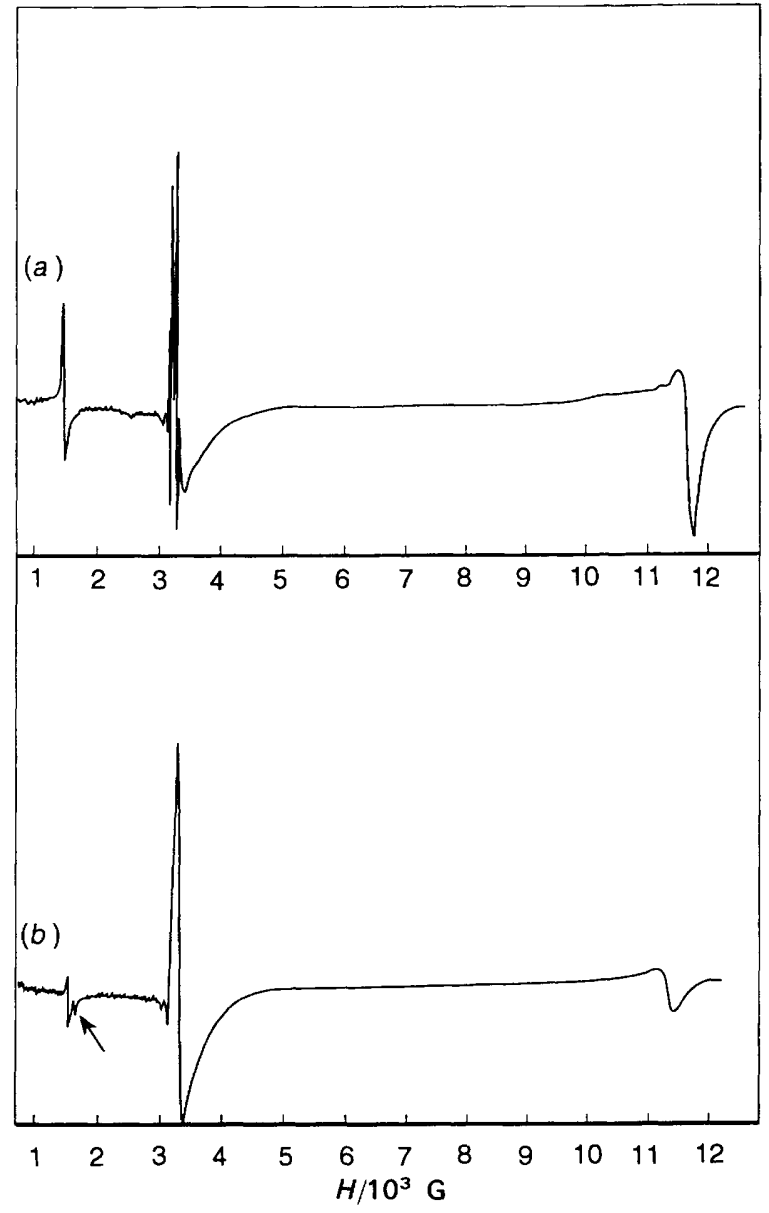

Fig. 6 EPR spectra for $\mathrm{AB}_{0.3}-T_{1.5}(a)$ and $\mathrm{AB}_{0.5}-T_{1.5}(b)$ at $14 \mathrm{~K}$

and the feature at ca. $5 \mathrm{kG}$ could be reproduced only using an axial $g$ tensor. In Table 2 the values of the parameters are listed together with those obtained in other matrices. The $D$ values for trapped $\mathrm{O}_{2}$ molecules are significantly smaller than that for 'free' $\mathrm{O}_{2}, 119 \mathrm{GHz}^{21}$

\section{NO}

The presence of NO in the samples is also revealed in the EPR spectra. The EPR spectra are shown for $\mathrm{AB}_{0.3}-T_{1.5}$ [Fig. $6(a)$ ] and $\mathrm{AB}_{0.5}-T_{1.5}$ [Fig. $6(b)$ ] measured at $14 \mathrm{~K}$. The latter spectrum reveals an asymmetrical signal with a large tail at high field, characteristic of NO, at $g \approx 2.0$ without con-

Table 2 EPR parameters of $\mathrm{O}_{2}$ molecules trapped in different matrices

\begin{tabular}{|c|c|c|c|c|c|c|c|}
\hline matrix & $g_{x}$ & $g_{y}$ & $g_{z}^{x}$ & $\begin{array}{c}\Delta H / \\
\mathrm{G}\end{array}$ & $\begin{array}{c}D / \\
\mathrm{GHz}\end{array}$ & $\begin{array}{c}E / \\
\mathrm{GHz}\end{array}$ & ref. \\
\hline $\mathrm{N}_{2}$ solid & 2.02 & 2.02 & 0.7 & 40 & 108 & - & 23 \\
\hline \multirow{2}{*}{$(<20 \mathrm{~K})$} & 2.0 & 2.0 & 2.0 & 25 & 108.3 & - & 24 \\
\hline & 2.0 & 2.0 & 2.0 & - & 107.1 & - & 25 \\
\hline $\mathrm{CO}$ solid & 2.02 & 2.02 & 0.7 & 80 & 108 & - & 23 \\
\hline$(<20 \mathrm{~K})$ & 2.0 & 2.0 & 2.0 & 400 & 108.5 & - & 24 \\
\hline $\begin{array}{c}\mathrm{KBrO}_{4} \\
\text { crystals } \\
(26 \mathrm{~K})\end{array}$ & 1.999 & 2.015 & 1.996 & - & 108.9 & 1.3 & 26 \\
\hline $\begin{array}{c}\mathrm{NaClO}_{3} \\
\text { crystals } \\
(4.2 \mathrm{~K})\end{array}$ & 2.004 & 2.006 & 2.003 & - & 112.2 & 0.135 & 27 \\
\hline $\begin{array}{c}\text { aluminium } \\
\text { borates } \\
(<20 \mathrm{~K})\end{array}$ & 2.02 & 2.02 & 0.673 & 320 & 109.3 & 0.075 & $-^{a}$ \\
\hline
\end{tabular}

${ }^{a}$ Present work. $x=z$ is the molecular axis.

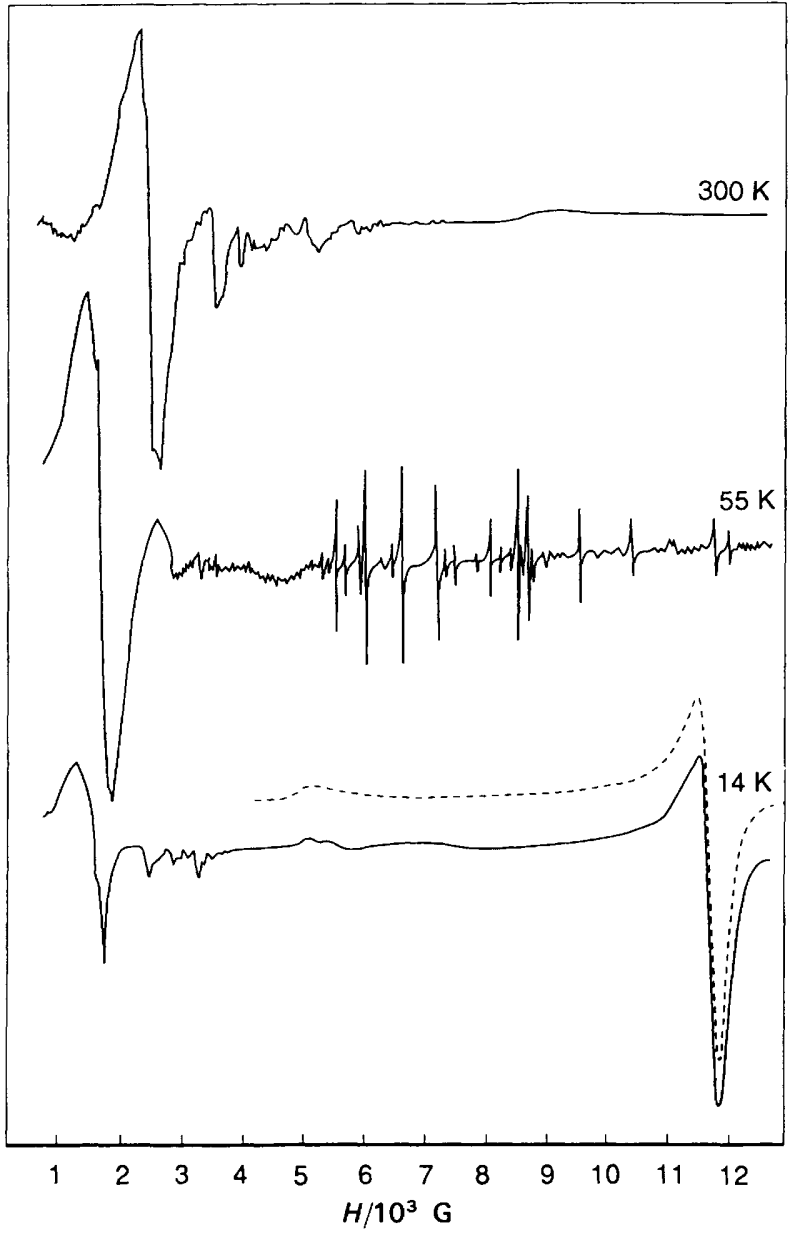

Fig. 7 Temperature dependence of the EPR spectra of $\mathrm{AB}_{0.2}-T_{2}$. The dotted line is the simulated signal for trapped $\mathrm{O}_{2}$ molecules using parameters listed in Table 2.

tamination from other signals. In Fig. $6(a)$ the NO signal is superimposed on the $\mathrm{NO}_{2}$ signal, as is the case in Fig. 5(c) (see insert). Close inspection of the spectra of other samples always showed a contribution from NO. In Table 3 the magnetic parameters are tabulated together with those of physisorbed NO molecules on $\gamma$-alumina, ${ }^{29}$ silica-magnesia, ${ }^{29}$ $\mathrm{MgO}^{16}$ and zeolites. ${ }^{13,31}$ Our values, estimated directly from the EPR spectra [Fig. 5(c) and 6], are in accordance with those measured in similar systems.

\section{Other Paramagnetic Species}

In the EPR spectra of samples heat treated between 150 and $200^{\circ} \mathrm{C}$ we observed EPR signals that we could not identify. As an illustration of this we refer to Fig. 7, where spectra are shown for the sample $\mathrm{AB}_{0.2}-T_{2}$. Broad lines are observed below ca. $5 \mathrm{kG}$. As can be seen from the figure, some lines shift to lower magnetic field values with decreasing temperature. It is suggested that these signals arise from pairs or clusters formed from paramagnetic species with $S=1 / 2$. In Fig. $5(a)$ there are some features at 5 and $8 \mathrm{kG}$ which might also be due to paramagnetic dimers or clusters. In some cases (at high NO concentrations) a well defined line at $g=4$ was observed [see peak in Fig. 6(b), indicated by an arrow], which might be a half-field signal from paramagnetic NO dimers. Peaks due to dimers of $\mathrm{NO}_{2}$ could be discerned in the fullfield region of the $\mathrm{NO}_{2}$ spectrum, especially at high $\mathrm{NO}_{2}$ concentration, as was observed by Schaafsma and Kommandeur. ${ }^{15}$

Finally, in the spectra of all samples in the region around $g \approx 2.0$, especially at low temperature, weak signals were 
Table 3 EPR parameters of NO molecules adsorbed on surface of various matrices (materials)

\begin{tabular}{|c|c|c|c|c|c|c|c|}
\hline oxide matrix & $g_{x}$ & $g_{y}$ & $g_{z}^{x}$ & $\begin{array}{c}A_{x} / \\
\mathrm{MHz}\end{array}$ & $\begin{array}{c}A_{y} / \\
\mathbf{M H z}\end{array}$ & $\begin{array}{c}A_{z} / \\
\mathrm{MHz}\end{array}$ & ref. \\
\hline$\gamma$-alumina $(77 \mathrm{~K})$ & 1.996 & 1.996 & 1.96 & - & 95 & - & 29 \\
\hline $\mathrm{MgO}(77 \mathrm{~K})$ & 1.995 & 1.995 & 1.91 & - & 93 & - & 16 \\
\hline $\begin{array}{l}\text { zeolites } \\
\quad(77 \mathrm{~K})\end{array}$ & $1.986-2.00$ & $1.978-1.998$ & $1.83-1.93$ & - & $85-95$ & - & 30,31 \\
\hline $\begin{array}{l}\text { aluminium borates } \\
(14 \mathrm{~K})\end{array}$ & 1.985 & 1.985 & $1.81-1.91$ & - & 85 & - & $-^{a}$ \\
\hline
\end{tabular}

${ }^{a}$ Present work. $x=z$ is the molecular axis.

observed superimposed on the strong signals of $\mathrm{NO}_{2}$ and NO. They are possibly related to some crystal defects or to organic and/or inorganic radicals produced during the synthesis.

\section{NMR on Aluminium Borates}

It was expected that changes in coordination of aluminium would be manifest clearly in ${ }^{27} \mathrm{Al}$ MASNMR spectra. This was indeed the case. The effect of heat-treatment temperature on the shape of the ${ }^{27} \mathrm{Al}$ MASNMR spectra is shown in Fig. 8 for samples without boron (spinning side bands are marked by asterisks). The dependence of the spectra on sample composition is illustrated in Fig. 9 for samples with different

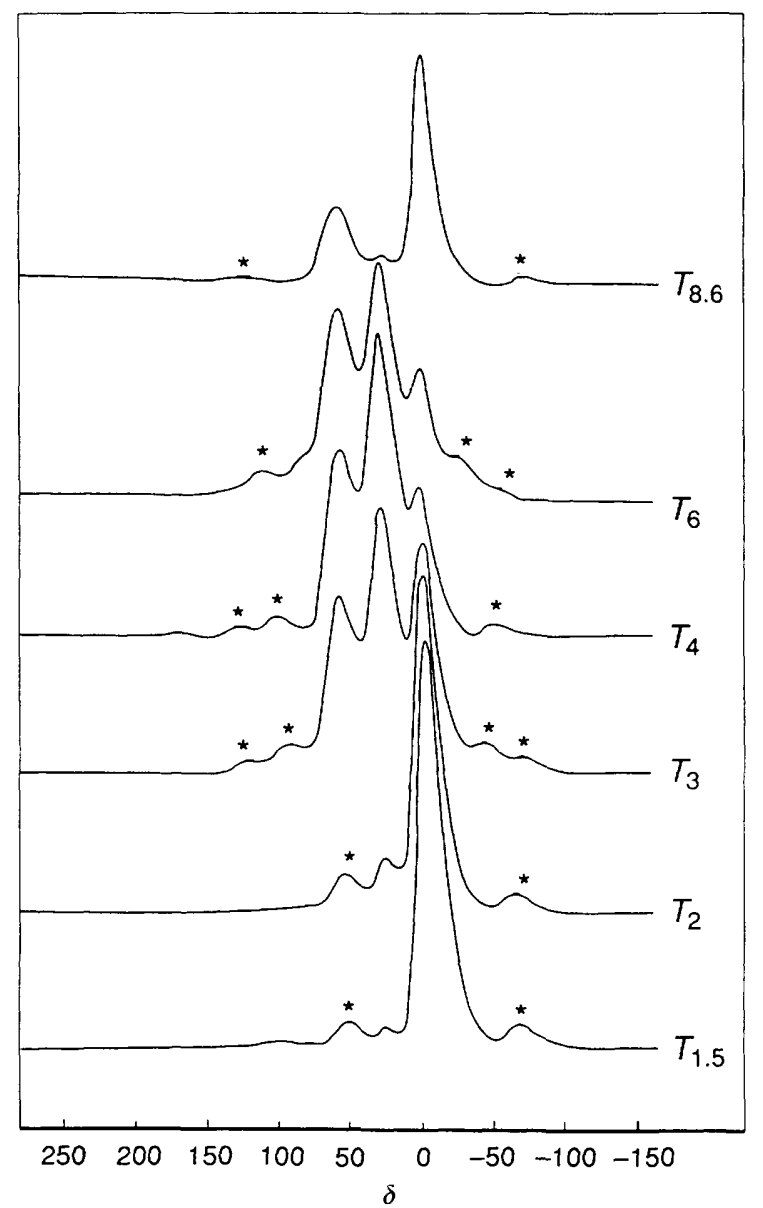

Fig. $8{ }^{27} \mathrm{Al}$ MASNMR spectra of $\mathrm{AB}_{0}$ samples at room temperature showing the effect of heat-treatment temperature. The spinning side bands are marked with asterisks and are outside the range of chemical shifts of the three $\mathrm{Al}$ resonances. boron contents and the same heating temperature $\left(T_{t}=\right.$ $400^{\circ} \mathrm{C}$ ). In all spectra three resonance peaks can be discerned with different intensities. The resonances at $0-8$ and 58-64 ppm are unanimously accepted to originate from octahedrally and tetrahedrally coordinated $\mathrm{Al}$, respectively. ${ }^{32-36}$ The third resonance at $c a .30 \mathrm{ppm}$ is consistent with the chemical shift of penta-coordinated $\mathrm{Al}$, as previously observed in NMR studies of crystalline materials with well defined penta-coordinated $\mathrm{Al}^{33,35}$ or in studies of disordered matrices, as gels and glasses, containing Al ions. ${ }^{36.37}$ Fig. 8 shows that mainly between 200 and $300^{\circ} \mathrm{C}$ pentacoordinated and tetra-coordinated $\mathrm{Al}$ are formed at the expense of octahedrally coordinated $\mathrm{Al}$. Above $800^{\circ} \mathrm{C}$ the spectrum corresponds to the NMR spectrum of $\gamma$-alumina, consisting of only tetrahedrally and octahedrally coordinated Al. Fig. 9 shows that the amount of penta-coordinated Al increases, whereas the fraction of tetra-coordinated $\mathrm{Al}$ decreases with increasing boron concentration.

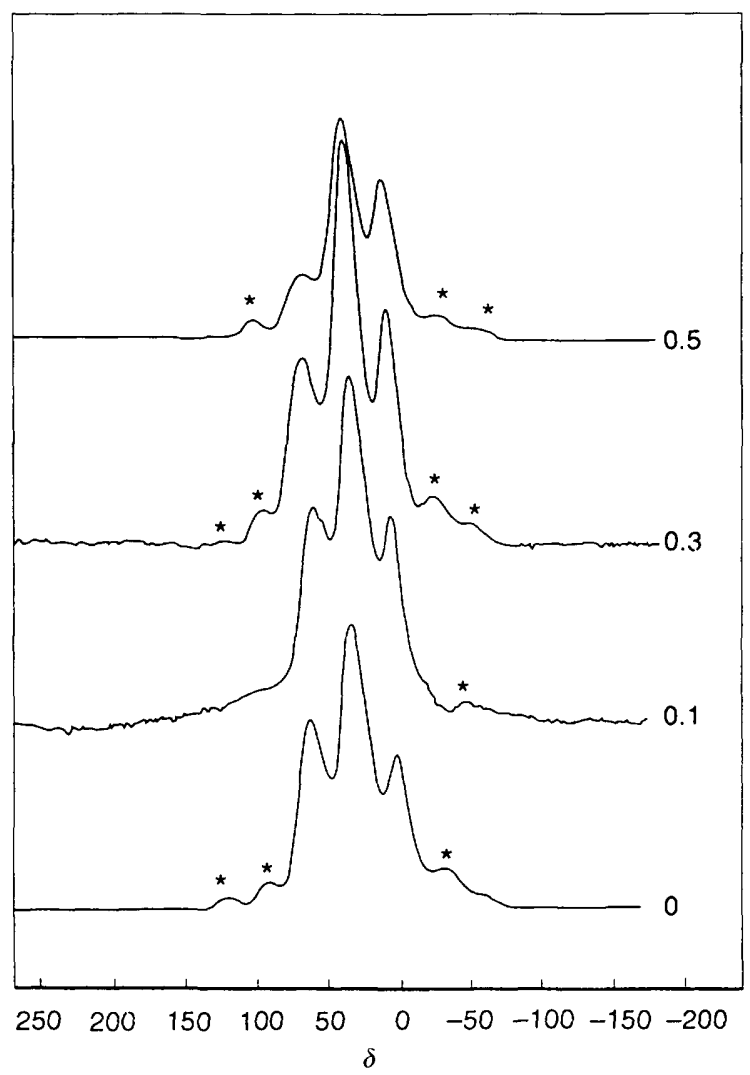

Fig. $9{ }^{27} \mathrm{Al}$ MASNMR spectra of $\mathrm{AB}_{x}-T_{4}$ samples showing the effect of the boron content; the value of $x$ is shown on the spectra. The spinning side bands are marked with asterisks and are outside the range of chemical shifts of the three Al resonances. 


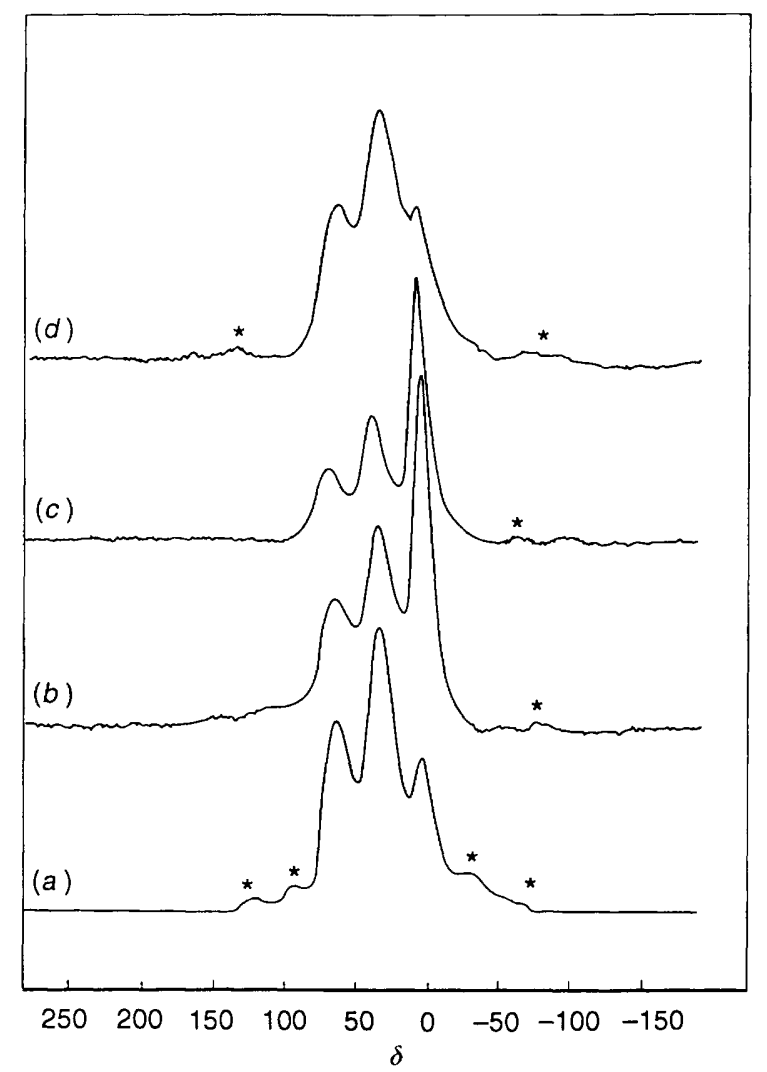

Fig. $10{ }^{27} \mathrm{Al}$ MASNMR spectra for the $\mathrm{AB}_{0}-T_{4}$ sample: $(a)$ as prepared, $(b)$ after 1 month and $(c)$ after 2 months storage in air, and $(d)$ after a new heat treatment at the same temperature $\left(400^{\circ} \mathrm{C}\right)$. The spinning side bands are marked with asterisks and are outside the range of chemical shifts of the three $\mathrm{Al}$ resonances.

For samples with $y \leqslant 7.5$ the ${ }^{27} \mathrm{Al}$ NMR spectra changed in time when these samples were exposed to air. This effect, also dependent on the boron content, is illustrated in Fig. 10 for the sample $\mathrm{AB}_{0}-T_{4}$. When, after the first measurement [Fig. 1O(a)], the sample is exposed to air, changes are observed caused by absorption of $\mathrm{H}_{2} \mathrm{O}$ molecules from the air [Fig. $10(b),(c)]$. The peak intensities of tetra- and pentacoordinated Al decrease, whereas the intensity of the peak due to octahedrally coordinated $\mathrm{Al}$ increases. After renewed heat treatment at the same temperature $\left(400^{\circ} \mathrm{C}\right)$ a similar ${ }^{27} \mathrm{Al}$ NMR spectrum was obtained to that measured for the as-prepared sample [Fig. 10(a)]. The same effect was observed recently for other aluminium oxide matrices. ${ }^{32}$

\section{Discussion}

\section{NMR}

During sol-gel synthesis the materials pass through several stages. ${ }^{38}$ In the starting solutions at room temperature the principal process is the hydrolysis reaction, during which the majority of the present cations become coordinated to hydroxy groups and water molecules. By increasing the temperature, condensation reactions evolve with the formation of $\mathrm{M}-\mathrm{O}-\mathrm{M}$ bonds and the production of water. These condensation reactions proceed during the drying of gels by successive heat treatments. At the end of the synthetic process amorphous porous xerogels are obtained.

Our experiments shed more light on what happens specifically during the synthesis of the xerogels.

Up to a heat-treatment temperature of $200^{\circ} \mathrm{C}$ decomposition reactions occur and glycerol is partially oxidized. The ${ }^{27}$ Al MASNMR spectra recorded for samples taken at heat- treatment temperatures of 150 and $200^{\circ} \mathrm{C}$ hardly differ (see Fig. 8).

A dramatic change in the local structure of the xerogels takes place between 200 and $300^{\circ} \mathrm{C}$, as is nicely illustrated by the ${ }^{27} \mathrm{Al}$ MASNMR spectra in Fig. 8. From these spectra it may be concluded that in the heat-treatment temperature range $300-600^{\circ} \mathrm{C}$ four- and five-coordinate $\mathrm{Al}$ are formed at the expense of six-coordinated Al. This is more clearly demonstrated in Fig. 11 where the change in the relative peak areas is plotted against the heat-treatment temperature. The relative intensities of the NMR peaks were determined by deconvolution of the spectra, assuming that the line shapes can be fitted with Gaussians. Since the electric field gradient is different at each of the three sites, the peaks have different and asymmetrical line shapes. These effects were taken into account by allowing the lines for each site to be a linear combination of one, two or three Gaussians with different widths and positions. In this way good fits were obtained.

Fig. 9 shows that four- and five-coordinate $\mathrm{Al}$ are also present in the boron-containing samples. The possibility that the resonance peak at $c a .30 \mathrm{ppm}$ is due to aluminium coordinated to boron atoms in the second coordination sphere ${ }^{6}$ can be ruled out because this resonance was also observed in pure alumina samples. Moreover, it was observed in ${ }^{29} \mathrm{Si}$ NMR of boron-containing MFI zeolites that boron present in the second coordination sphere of Si had no effect on the Si chemical shift. ${ }^{39}$ Therefore, we do not expect any effect on the Al chemical shifts either. From Fig. 9 it can furthermore be inferred that the boron ions prefer fourinstead of six-coordination (see spectrum of sample $\mathbf{A B}_{0.5}$ ).

The decrease in the number of aluminium atoms in the four- and five-coordinate ion sites in samples exposed to air (so-called air-equilibrated gels), suggests that low-coordinate $\mathrm{Al}$ atoms are predominantly located at the surface of the xerogels. It is known that these four- and five-coordinate $\mathrm{Al}$ atoms at the surface are associated with the catalytically active sites. ${ }^{1,40}$ The partial rehydroxylation that takes place when the sample is exposed to air is the principal factor involved in the different results reported in the literature for similar materials. ${ }^{6,7}$ The difference in preparation procedure seems to be of minor importance.

Not only is the local structure changed during the synthesis of xerogels but also the internal porosity. By increasing

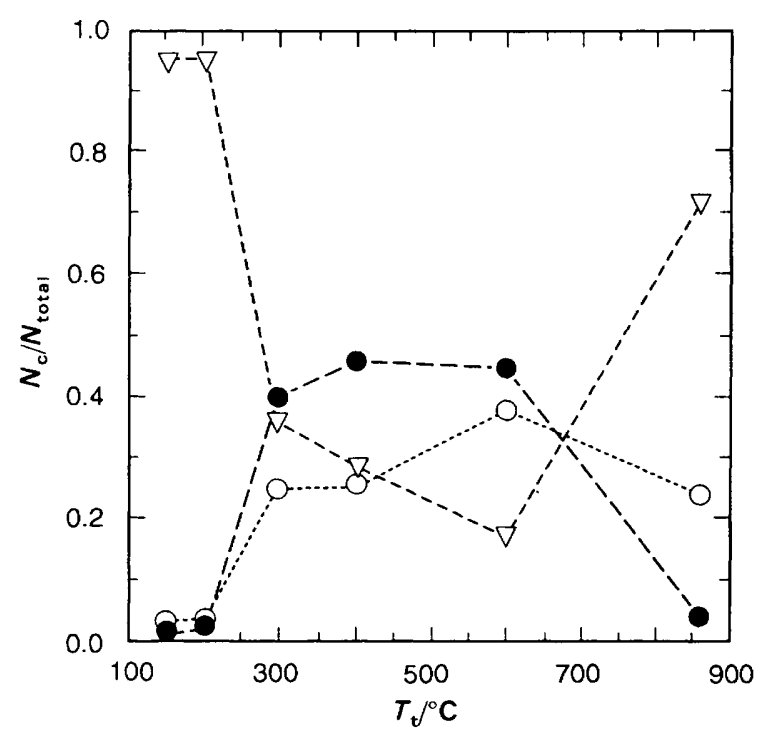

Fig. 11 Fraction of $(\nabla)$ hexa-, $(O)$ penta- and $(O)$ tetra-coordinated $\mathrm{Al}$ ions as a function of heat treatment temperature $(T)$. The dotted lines are guides to the eye. 
the heat-treatment temperature the dimensions of the pores diminish, the surface area decreases and the density of the samples increases (skeletal densification). After $3 \mathrm{~h}$ heat treatment at $860^{\circ} \mathrm{C}$ the ${ }^{27} \mathrm{Al}$ NMR spectra of the samples (Fig. 8) are identical to that of $\gamma$-alumina, proving that the amorphous alumina xerogels had been transformed into polycrystalline alumina.

\section{EPR}

The EPR results offer us new, important information about the evolution of catalytically active sites. The gaseous paramagnetic species that are produced by the decomposition reactions interact with these active sites before they change their initial configuration by structural relaxation or as a result of interactions with other non-paramagnetic molecules such as water.

As indicated above, the mobility of physisorbed $\mathrm{NO}_{2}$ molecules depends on the heat-treatment temperature. Their mobility, determined by the strength of their interactions with the surfaces of the xerogels, is revealed by the temperature dependence of the EPR spectra shown in Fig. 3 and Fig. 4. $\mathrm{NO}_{2}$ molecules in samples treated at low temperatures have a higher mobility than in samples treated at higher temperatures. For instance in the sample $\mathrm{AB}_{0.2}-T_{1}$ the $\mathrm{NO}_{2} \mathrm{~mol}-$ ecules at $125 \mathrm{~K}$ rotate isotropically, whereas in the sample $\mathrm{AB}_{0.2}-T_{4}$ at the same temperature the $\mathrm{NO}_{2}$ molecules rotate anisotropically around an axis parallel to the interatomic axis between the oxygen atoms (denoted as the $y$ axis). For samples with $y \leqslant 1.5$ the mobility of the $\mathrm{NO}_{2}$ molecules is comparable to the mobility observed for $\mathrm{NO}_{2}$ adsorbed on Vycor glass ${ }^{19}$ or on zeolites, ${ }^{30}$ but for samples with $y>2$ the mobility of $\mathrm{NO}_{2}$ is lower. At high treatment temperatures the samples become to a great extent dehydroxylated and accordingly the interaction between the $\mathrm{NO}_{2}$ molecules and the surface becomes stronger, thus restricting their mobility. For the sample $\mathrm{AB}_{0.2}-T_{4}$ the $\mathrm{NO}_{2}$ molecules move anisotropically even at room temperature (see Fig. 4).

As shown in Table 1, the magnetic parameters of $\mathrm{NO}_{2}$ in aluminium borate xerogels are comparable to the values observed for similar systems. Hence the adsorbed $\mathrm{NO}_{2}$ molecules are not greatly distorted by the aluminium borate matrix. Pietrzak and Wood ${ }^{17}$ concluded from this that the majority of the $\mathrm{NO}_{2}$ molecules dimerize at low temperature and are surrounded by several $\mathrm{N}_{2} \mathrm{O}_{4}$ molecules which have condensed on the walls of the zeolites studied by them, thus shielding the $\mathrm{NO}_{2}$ molecule from strong cation interactions. The same conclusion may be drawn for the system investigated by us. Fig. 6 shows that on increasing the boron content the $\mathrm{O}_{2}$ EPR signal decreases. This can be rationalized as follows. When the boron content increases less $\mathrm{O}_{2}$ will be produced by the decomposition of $\mathrm{Al}\left(\mathrm{NO}_{3}\right)_{3}$ because its concentration decreases as the boron content increases. The $\mathrm{O}_{2}$ molecules produced will be partly used in the oxidation of glycerol, the concentration of which is the same in all samples. Thus the $\mathrm{O}_{2}$ signal intensity observed will decrease as the boron content increases.

This is not contradicted by the experiment described in Fig. 5, where we see that the $\mathrm{O}_{2}$ EPR signal increases after a renewed heating procedure. We must remember that in this experiment the sample has been placed in a closed evacuated tube, so that the decomposition products can escape into the empty space above the sample, especially the non-polar $\mathrm{O}_{2}$ molecules. The polar molecules such as NO are preferentially fixed on coordinatively unsaturated active sites $\left(\mathrm{Al}^{3+}, \mathrm{B}^{3+}\right)$, developed during the heating process. Thus the $\mathrm{O}_{2}$ molecules that have escaped cannot be consumed in the pyrolysis of glycerol. After cooling the sample to $14 \mathrm{~K}$ the $\mathrm{O}_{2}$ molecules will condense on the surfaces, and will give rise to an enhanced EPR signal.

At heating temperatures below $200^{\circ} \mathrm{C}$ we observed in the EPR spectra signals that we believe to arise from species with $S \geqslant 1$. From the ${ }^{27}$ Al NMR spectra it can be concluded that below $200^{\circ} \mathrm{C}$ only a small number of low-coordinate $\mathrm{Al}$ species are present (see Fig. 8). At the beginning they are not uniformly distributed over the surface area of the pores, but will appear in zones in which the hydroxylation process was most effective. From structural studies it was found that one oxygen anion vacancy can create as many as three fivecoordinate Al sites. ${ }^{37}$ The polar paramagnetic species, especially the very reactive NO molecules, will react with these active sites and form paramagnetic clusters with $S \geqslant 1$. The formation of these clusters is also favoured by the high gas pressure in the pores, which are closed at this temperature. The sharp signal at $g=4$, indicated by an arrow in Fig. 6, may arise from NO dimers. Pairs of $\mathrm{NO}_{2}$ molecules can also be formed, especially when the concentration of $\mathrm{NO}_{2}$ is high. ${ }^{15}$ We found evidence for this in our spectra, measured below $20 \mathrm{~K}$.

Note that we found no evidence in our experiments of the presence of $\mathrm{O}_{2}{ }^{-}$. When $\mathrm{O}_{2}$ is adsorbed on 'clean' surfaces of activated oxide materials, usually an electron is transferred to $\mathrm{O}_{2} \cdot{ }^{41}$ In our experiments the surfaces will be preferentially covered by polar molecules such as $\mathrm{NO}, \mathrm{N}_{2} \mathrm{O}_{4}, \mathrm{NO}_{2}, \mathrm{OH}^{-}$ or $\mathrm{H}_{2} \mathrm{O}$, so that the $\mathrm{O}_{2}$ molecules are physisorbed on top of them and no electron transfer to $\mathrm{O}_{2}$ takes place.

The appearance of the multiline spectrum of $\mathrm{O}_{2}$ was a surprising result. The multiline spectrum arises through the coupling of the rotational angular momentum, which is quenched in the liquid or solid phase, with the electronic spin and orbital angular momentum. ${ }^{21}$ This spectrum could be observed only over a narrow temperature interval of $15^{\circ} \mathrm{C}$. If the $\mathrm{O}_{2}$ concentration is high, collisional broadening will occur. On cooling the sample, the concentration of $\mathrm{O}_{2}$ decreases by condensation of $\mathrm{O}_{2}$ molecules on the surfaces of the pores. A point is then reached where the concentration of $\mathrm{O}_{2}$ is large enough and the relaxation times long enough to make detection of the EPR spectrum of gaseous $\mathrm{O}_{2}$ possible. Further lowering of the temperature leads to total condensation and to the disappearance of the gaseous EPR spectrum and to the appearance of the EPR spectrum of $\mathrm{O}_{2}$ in the condensed phase.

The zero-field splitting $(D)$ of $\mathrm{O}_{2}$ in the gaseous state is 119 $\mathrm{GHz}^{21}$ For $\mathrm{O}_{2}$ in our system the $D$ value amounts to 109 $\mathrm{GHz}$. The reduction of the value of $D$ has been attributed to torsional oscillation of the $\mathrm{O}_{2}$ molecules in a potential well provided by the matrix. ${ }^{42}$ Table 2 shows that the same effect has been observed for $\mathrm{O}_{2}$ trapped in other matrices.

\section{Conclusion}

Our EPR studies on aluminium borate materials show that the paramagnetic products of decomposition reactions in sol-gel processing of amorphous xerogels can be used as EPR probes for the study of the active sites developed during the synthesis on the surface of the pores. The strength of the interactions between the active sites and the paramagnetic products are reflected in the shape of the EPR spectra of the adsorbed molecules.

The ${ }^{27} \mathrm{Al}$ MASNMR spectra reflect directly the changes in $\mathrm{Al}$ coordination during the heating procedure. In the temperature range from 200 to $300^{\circ} \mathrm{C}$ four- and five-coordinate Al species are formed, which, on exposure to air, are partially transformed again to six-coordinate $\mathrm{Al}$ by absorption of water present in the air. This observation stresses the importance of working under well defined conditions in cases where 
the materials studied have high surface area. Some conflicting results in the literature may be ascribed to air-equilibration of the samples.

Finally, the simultaneous use of NMR and EPR techniques is shown to be a powerful tool for the study of the active sites in amorphous and crystalline materials.

The authors thank Mr. A. A. K. Klaassen, Mr. G. E. Janssen and Mrs. G. H. Nachtegaal for their skilful experimental assistance.

\section{References}

1 H. Knözinger, in Catalysis by Acids and Bases, ed. B. Imelik, C. Naccache, Y. Condurier, B. Tarit and J. C. Vedrine, Elsevier, Amsterdam, 1985, p. 111.

2 G. Pajonk, M. Repellin and S. J. Techner, Bull. Soc. Chim. Fr., 1976, 1333.

3 G. Tournier, M. Lacroix-Repellin, G. M. Pajonk and S. T. Teichner, Preparation of Catalysts $I V$, ed. B. Delmon, P. Grange, P. A. Jacobs and G. Poncelet, Elsevier, Amsterdam, 1987 , p. 333.

4 S. F. Mitchel, G. Marcelin and J. G. Goodwin, J. Catal., 1987, $105,521$.

5 D. L. Cocke, E. D. Johnson and R. P. Merrill, Catal. Rev. Sci. Eng., 1984, 26, 163.

6 K. P. Peil, L. G. Galya and G. Marcelin, J. Catal., 1989, 115, 441.

7 F. Abbattista, A. Delmastro, G. Gozzelino, D. Mazza, M. Vallino, G. Busca and V. Lorenzelli, J. Chem. Soc., Faraday Trans., 1990, 86, 3653.

8 A. Delmastro, G. Gozzelino, D. Mazza, M. Vallino, G. Busca and V. Lorenzelli, J. Chem. Soc., Faraday Trans., 1992, 88, 2065.

9 S. Tanabe, K. Hirao, N. Soga and T. Hanada, J. Solid State Chem., 1992, 97, 481.

10 R. Bechara, A. Aboukais and J. P. Bonnelle, J. Chem. Soc. Faraday Trans., 1993, 89, 1257.

11 J. G. Darab and R. K. MacCrone, Phys. Chem. Glasses, 1991, 32, 191.

12 S. Ikoma, K. Kawakita and H. Yokoi, J. Non. Cryst. Solids, $1990,122,183$.

13 G. R. Bird, J. C. Bird, A. W. Jache, J. A. Hodgson, R. F. Curl, A. C. Kunkle, J. W. Bransford, J. Rastrup-Anderson and J. Rosenthal, J. Chem. Phys., 1964, 40, 3378.

14 T. J. Schaafsma, G. A. van der Velde and J. Kommandeur, Mol. Phys., 1968, 14, 501.
15 T. J. Schaafsma and J. Kommandeur, Mol. Phys., 1968, 14, 517.

16 J. H. Lunsford, J. Colloid Interface Sci., 1968, 26, 355.

17 T. M. Pietrzak and D. E. Wood, J. Chem. Phys., 1970, 53, 2454.

18 M. Iwaizumi, S. Kubota and T. Isobe, Bull. Chem. Soc. Jpn., $1971,44,3227$.

19 M. Shiotani and J. H. Freed, J. Phys. Chem., 1981, 85, 3873.

20 R. Beringer and J. G. Castle, Phys. Rev., 1951, 81, 82.

21 M. Tinkham and M. W. P. Standberg, Phys. Rev., 1955, 97, 951.

22 G. M. Graham, J. S. M. Harvey and H. Kiefte, J. Chem. Phys., $1969,52,2235$.

23 R. Simoneau, J. S. M. Harvey and G. M. Graham, J. Chem. Phys., 1971, 54, 4819.

24 H. Kon, J. Am. Chem. Soc., 1973, 95, 1045.

25 S. Hirokawa, J. Phys. Soc. Jpn., 1974, 37, 897.

26 J. R. Byberg, Chem. Phys. Lett., 1978, 57, 579.

27 N. Bjerre, J. Chem. Phys., 1982, 76, 3347.

28 C. P. Keijzers, E. J. Reijerse, P. Stam, M. F. Dumont and M. C. M. Gribau, J. Chem. Soc., Faraday Trans. 1, 1987, 83, 3469.

29 J. H. Lunsford, J. Catal., 1969, 14, 379.

30 J. H. Lunsford, J. Phys. Chem., 1970, 71, 1519

31 P. H. Kasai and R. J. Bishop Jr., J. Am. Chem. Soc., 1972, 94, 5560.

32 M. E. Smith, Appl. Magn. Reson., 1993, 4, 1.

33 L. B. Alemany and G. W. Kirker, J. Am. Chem. Soc., 1986, 108 6158 .

34 D. Massiot, A. Kahn-Harari, D. Michel, D. Müller and F. Taulelle, Magn. Reson. Chem., 1990, 28, S82.

35 M. E. Smith and S. Steuernagel, Solid State NMR, 1992, 1175.

36 A. D. Irwin, J. S. Holmgren and J. Jonas, J. Mater. Sci., 1988, 23, 2908

37 T. E. Wood, A. R. Siedle, J. R. Hill, R. P. Skarjune, C. J. Goodbrake, Mater. Res. Soc. Symp. Proc., 1990, 180, 97.

38 C. J. Brinker, in Glass: Science and Technology, ed. D. R Uhlmann and N. J. Kreidl, Academic Press, New York, 1990, vol. 4 A, p. 169.

39 R. de Ruiter, A. P. M. Kentgens, J. Grootendorst, J. C. Jansen and H. van Bekkum, Zeolites, 1993, 13, 128.

40 H. Yong, B. Coster, F. R. Chen, J. G. Davis and J. J. Fripiat, New Frontiers in Catalysis, ed. L. Guczi, F. Solymosi and P. Tétényi, Elsevier, Amsterdam, 1993, p. 1159.

41 M. Che and A. J. Tench, Adv. Catal., 1983, 32, 1.

42 H. Meyer, M. C. M. O'Brien and J. H. van Vleck, Proc. R. Soc. London, Ser. A, 1957, 243, 414.

Paper 4/02417F; Received 25th April, 1994 